\title{
Ontogénesis humana y filosofía del sujeto en la teoría mimética de René Girard
}

\section{(Human ontogenesis and philosophy of subject in René Girard's mimetic theory)}

\author{
Agustín Moreno Fernández
}

Recibido: 28 de febrero de 2013

Aceptado: 22 de mayo de 2013

\section{Resumen}

La obra girardiana no es sistemática. El análisis y la síntesis de contenido de sus textos es el objeto de esta investigación. Pretendemos aquí exponer y clarificar su filosofía mimética, tanto su teoría sobre la formación de los individuos, como su filosofía interdividual del sujeto, además de contextualizarla dentro del giro intersubjetivo de la filosofía contemporánea.

Palabras clave: teoría mimética, René Girard, ontogénesis, filosofia de la intersubjetividad.

\begin{abstract}
Girard's work is not systematic. Our research's works analyse and synthesize the contents of his texts. The purpose of this article is to expose and to clarify his mimetic theory framework, his theory about the human ontogenesis and his interdividual philosophy about the subject, contextualising this in the intersubjective turn of the contemporary philosophy.
\end{abstract}

Keywords: mimetic theory, René Girard, ontogenesis, philosophy of intersubjectivity. 


\section{El encaje entre antropogénesis y ontogénesis}

Aunque la obra de Girard aún no tiene demasiada repercusión en España, podemos decir que su teoría del mecanismo del chivo expiatorio, divulgada a través de sus obras más conocidas, hace que asociemos más a este pensador, y no sin razón, con un planteamiento acerca de los orígenes de la cultura y de la especie humana, cuestionando, por otra parte, las teorías clásicas del contrato social. Y, sin embargo, quedarse sólo aquí, en su teoría filogenética, sería no tener una perspectiva completa.

Cambiar de nivel de análisis no supone un cambio de teoría. Si, al hablar de la filogénesis humana y la posterior evolución de la especie, en torno al mecanismo del chivo expiatorio y los sacrificios rituales, la "grasa" asociada al funcionamiento de los engranajes sería el hipermimetismo humano, éste seguiría siendo capital en la conformación de individuos de la especie. La imitación sería primera, fundamental (Girard 1995, p. 114). Cambiar de escala no supondría dejar de ver los orígenes sacrificiales y violentos de la humanidad, como el abordar aquellos no implica restar relevancia al mimetismo. Hablaremos de la indispensabilidad de la mímesis en los neonatos y su posterior infancia y desarrollo. Tendremos en cuenta aquí un tipo especial de neuronas, las neuronas espejo, que apoyarían la tesis de la fundamentalidad del comportamiento imitativo de los seres humanos en su constitución como tales. También prestaremos atención a los signos indicativos y evocadores, a nivel ontogenético, del mecanismo del chivo expiatorio, ligado en la hipótesis mimética a nuestra consolidación como especie. Para disipar cualquier duda, Girard no dice nunca que la violencia sea lo fundamental en la antropogénesis y el deseo mimético en la ontogénesis: "la violencia es la continuación del deseo mimético por medios brutales. No es la violencia la que juega el rol principal en mi perspectiva; sólo la mimesis tiene ese rol" (Girard 2011, pp. 80-81).

La noción de "mecanismo" o "ciclo mimético", ilustra la unidad teórica de la hipótesis de Girard, ya que comprende la vasta secuencia de fenómenos que se suceden entre el deseo mimético, la rivalidad mimética y su contagio, la crisis mimética o sacrificial y la resolución de ésta mediante el chivo expiatorio (Girard 2004a, p. 51; Girard 2002b, p. 60)1. Incluso en sociedades como la nuestra, en las que no dependemos de crímenes colectivos o sacrificios para garantizar la estabilidad social, y también a nivel interpersonal, aún hoy podría detectarse nuestra propensión mimética a la reciprocidad y a las dinámicas de la violencia. Como señala la pensadora de inspiración girardiana M. L. Martínez, en su estudio antropológico

\footnotetext{
1 Girard es ambivalente a la hora de determinar si el deseo mimético es solamente humano. Parecen más razonables las afirmaciones que establecen un sustrato anterior al deseo, las "interferencias miméticas", presentes tanto en animales, como en primates y homínidos, pero el autor sólo traza esta distinción en algunas ocasiones (Girard 1997, p. 204).
} 
y filosófico de la violencia y la educación: en tanto que toda antropogénesis comporta una concesión a la violencia sacrificial, "debemos encontrar el eco sobre el plano de la ontogénesis" (Martinez 1996, p. 71).

El mimetismo humano y el deseo mimético serían algo fundamental tanto desde un punto de vista biológico, como social y cultural: en el aprendizaje de la alimentación y del lenguaje; en la empatía con los demás o en la conformación de nuestras pertenencias grupales o señas identitarias que, para la teoría mimética, pasan inexcusablemente por el deseo de ser como los otros y no están, ni mucho menos, exentas de rivalidades, conflictos y violencia, incluso en sus formas más veladas. En opinión de Girard el deseo mimético habría jugado un rol fundamental en la cultura humana desde siempre. Hoy la comunicación implementada por las nuevas tecnologías favorece, acelera y amplifica, de manera excepcional, algunas de sus manifestaciones, lo que para muchos quiere decir que el deseo mimético sería, más bien, un fenómeno característico de nuestra época en especial. Sin embargo, Girard insiste en que, aunque las tecnologías de la comunicación nos obligan a ver el deseo mimético, no son estas quienes lo engendran (Anspach 2008, p. 198).

El pensador se muestra satisfecho por la fortuna que habría tenido su teoría a la hora de describir la gran relevancia de los mecanismos miméticos en el comportamiento humano, anticipándose a los descubrimientos neurológicos recientes que la podrían haber confirmado, incidiendo en la idea de que la imitación es primera y medio esencial del aprendizaje (Girard 2010a, p. 10). Nuestra especial capacidad para la imitación sería lo que nos hace sobrepasar la animalidad, lo más dinámico de la inteligencia humana para bien y para mal. Llevándonos más lejos en la violencia, la brutalidad y la intensidad de la rivalidad mimética. El ser humano sería el animal que, sin un freno instintivo, puede ir a la deriva, abandonado a la fatalidad de su mimetismo violento (Girard 2006a, pp. 17-18). Aunque el deseo mimético pueda resultar pernicioso, no sería malo en sí mismo. Al contrario, afortunadamente, el hombre no podría renunciar a él, como no puede hacerlo con la alimentación o el sueño. Gracias a la imitación también serían posibles: el aprendizaje de la lengua y de la cultura; la innovación, tanto a nivel individual como grupal, y la incorporación de los seres humanos a una tradición susceptible de ser legada y adoptada por otros individuos y generaciones (Girard 2006b, p. 55).

Una vez que el ser humano sacia sus necesidades naturales y satisface las necesidades primordiales, o incluso antes, desearía intensamente, aunque sin saber con exactitud ni con certeza qué. Carece de instinto que le guíe pero, en cambio, tiene el deseo. Tiene el deseo, pero no tendría deseos propios y para poder desear recurre a los demás para que le presten los suyos (Girard 2002b, p. 33): "el hombre [...] es aquel que fundamentalmente no sabe qué desear" (Anspach 2008, p. 183). El hombre desearía un ser del que se siente privado (deseo metafísico) y cree encontrarlo en alguien, de quien espera saber lo que hay que desear para adquirir ese ser (ese alguien, además de modelos determinados es la sociedad y la cultura). Por ello, los 
objetos que el modelo posea son asociados por el sujeto con el ser del modelo al que aspira. Para Girard el deseo es esencialmente mimético, pero más allá del mimetismo del deseo infantil, considera que el deseo adulto también lo es (deseo mimético universal).

\section{Mimetismo y desarrollo ontogenético}

Aunque Girard no tiene al niño como objeto de estudio, en las obras girardianas encontramos menciones explícitas a esta cuestión referidas principalmente, como cabía esperar, al mimetismo. Nos referiremos a estas consideraciones del propio pensador, apoyados en dos ponencias que, sobre pedagogía, tuvieron lugar en el Colloque du Cerisy de 1983 consagrado a Girard. C. Seibel, preocupado por la problemática del aprendizaje escolar, señala cómo, a través de los estadios del desarrollo del niño, descritos, entre otros, por A. Gessell, J. Piaget o H. Wallon, se pone de manifiesto claramente la importancia que estos investigadores han conferido a los fenómenos de imitación (Seibel 1985, p. 288). L. Morin, en su pretensión de elaborar una primera tentativa de aplicación de la teoría girardiana al niño, apela a la psicología genética de Piaget para dar amplitud científica a los argumentos de Girard, al tiempo que quiere proporcionar a las descripciones de esta psicología lo que considera que le falta a través de la teoría mimética (Morin 1985, p. 299).

La imitación sería el mecanismo mediante el cual el niño pequeño puede empatizar, conocer algo de los sentimientos del otro. La actitud de los bebés, cuando hacen el acercamiento entre el comportamiento de sus prójimos y los efectos inducidos por el hecho de imitarlos, sería fundamental para el desarrollo ulterior de la intersubjetividad de la comunicación y de la cognición social. El caso del autismo, en tanto que disminución considerable de la actividad relacional, pondría de manifiesto la relevancia de la capacidad de imitar. No poder imitar sería el signo de un grave déficit cultural (Girard 2004a, p. 53. Girard 2002a, pp. 291-314). Si los hombres cesaran de imitar, todas las formas culturales se desvanecerían porque "no hay nada o casi nada en los comportamientos humanos que no sea aprendido y todo aprendizaje se reduce a la imitación" (Lazzeri 2010, p. 22. Girard 1982, p. 17).

Si el deseo humano no fuera mimético, si los niños no tomaran como modelo necesariamente a las personas que les rodean, la humanidad no tendría lenguaje ni cultura. Por eso sería en este terreno donde hay mayor incertidumbre y necesidad de modelos. Por tanto, la única cultura que es realmente nuestra, no es aquella en la que hemos nacido, sino aquella cuyos modelos imitamos a la edad en la que tenemos una capacidad de asimilación mimética máxima (Girard 2002b, p. 33) ${ }^{2}$. En

\footnotetext{
2 No obstante Girard también debería considerar que, ya desde la etapa fetal, el individuo estaría afectado por los factores culturales (Morin 2000, p. 4).
} 
consecuencia, las primeras pertenencias serían fundamentales para el aprendizaje y la educación, asegurando además la inserción en la vida social. La familia proporciona los primeros modelos. Mediante la imitación del padre y de la madre el niño aprende los gestos elementales de la vida. En la escuela, también se proporcionarán modelos necesarios para que los niños se conviertan en adultos, capacitados para formar parte de la sociedad. Y el medio profesional también seguirá siendo una fuente de aprendizaje (Girard 2004b, p. 22).

Para Girard, imitación y aprendizaje son indisociables y la innovación se abre paso a través de ellos, sin perder nunca de vista la naturaleza mimética del deseo desde los primeros estadios del desarrollo humano (Girard 2004a, p. 53). Reprocha a la mayoría de los psicólogos su error al creer que la imitación sólo nos afecta superficialmente. Si fuera así, no se podría explicar que nuestros mejores modelos educativos tuviesen una influencia significativa sobre nosotros (Girard 2002a, p. 201). La cuestión de los modelos es capital, en la medida en que su imitación es clave en nuestra constitución individual y social. Y aquí entra en juego la suerte o la fatalidad de tener buenos o malos modelos en el proceso educativo (Girard 2010a, p. 155).

¿Cuándo empiezan los niños a imitar? Girard conoce los experimentos de los psicólogos del comportamiento que indican que los recién nacidos son ya capaces de imitar (Girard 2004a, p. 55). Por ejemplo, tras ver que alguien les saca la lengua reaccionan a este comportamiento sacándola ellos también (un fenómeno no privativo de neonatos humanos). O. Maurel sostiene también que "el niño aprende todo por imitación", que "ha nacido imitador bien antes de ser capaz de querer imitar", y evoca este tipo de experimentos (Maurel 2009, p.116). Girard acusa la ausencia de esta constatación en la psicología de Piaget y le sirve para apoyar la idea de que el mimetismo no es aprendido, sino innato, y que permanece durante toda la vida (Girard 2009b, pp. 8-9). Como señala L. Morin, Girard coincide con Piaget, y éste a su vez con otros (Guillaume, Wallon, Stern, Ferretti...) al reconocer la importancia de la imitación: "el psicólogo suizo ha analizado finamente la imitación pre-verbal y prerepresentacional en el bebé: "Llamamos imitación al acto por el cual un modelo es reproducido, lo que no implica en nada la representación de este modelo"', aunque, como decimos, Piaget se habría quedado corto (Morin 1985, pp. 300-301).

Hay autores como H. Wallon que permiten precisar en la psicogénesis infantil procesos "que son extremadamente próximos a los evocados en la obra de R. Girard" (Seibel 1985, p. 290) y que, aunque ninguna investigación se vincula explícitamente a la hipótesis girardiana, "la localización de situaciones miméticas en el aprendizaje y en la educación de los niños constituye [...] una aportación esencial de la psicología en el campo del desarrollo de los niños de menor edad" (Seibel 1985, p. 291). El hipermimetismo humano sería imprescindible para la adquisición de los comportamientos culturales y la correcta inserción de cada individuo en su 
cultura (Girard 1982, p. 327). Más allá de los deseos, que niños, adolescentes o adultos reciben de sus modelos, están en juego "multitud de comportamientos, actitudes, saberes, prejuicios, preferencias, etcétera, en el seno de los cuales el préstamo de mayores consecuencias, el deseo, pasa a menudo inadvertido" (Girard 2002b, p. 33). La misma adquisición de la consciencia humana para Girard no se adquiere por la razón, sino por el deseo imitativo (Girard 2010a, p. 63).

No obstante, en todos estos préstamos, imitaciones e interacciones, incluidas las educativas, uno de los más importantes y frecuentes fenómenos que se darían son los procesos latentes de "double bind", también en la infancia, que puede traducirse como imperativo contradictorio o doble imperativo contradictorio (doble vínculo o doble constreñimiento), análogos a los descritos por G. Bateson y la Escuela de Palo Alto y a los que también se refiere Girard (Seibel 1985, p. 291). El niño tendría una relación de mediación externa con los adultos, es decir, hay una distancia "espiritual" o diferenciación suficiente entre ellos, para que no se conviertan en competidores (al contrario de la mediación interna). Una distancia psíquica que posibilitaría una imitación positiva (con los demás niños será más fácil una relación de mediación interna, y por tanto de rivalidad (Girard 2004a, pp. 55-56)). Sin embargo el mundo infantil de relaciones con los adultos no está exento de dificultades, como tampoco lo está con sus semejantes: "En su universo, el niño disfruta de la felicidad y de la paz. Pero este universo ya está amenazado. Cuando la madre niega un beso a su hijo ya interpreta el doble papel, propio de la mediación interna, de instigadora del deseo y de centinela implacable. La divinidad familiar cambia brutalmente de aspecto" (Girard 1985, p. 37). L. Morin cita a Piaget quien, a su vez, sigue a Bovet (y éste a Rollin, Descartes o Tomás de Aquino), afirmando que "el respeto consiste en una combinación sui generis de temor y de amor" (Morin 1985, p. 310). Pero a juicio del primero sólo la mediación mimética puede dar cuenta de manera impecable de la contradicción. Según Piaget los padres son dioses para los niños, mediadores externos en terminología girardiana y, gracias a ellos y su intermediación, el niño se enseña en el ser y en la existencia. Sin embargo, simultáneamente, el adulto corre el riesgo de ser percibido como el que siempre puede obstruir el acceso al niño para la realización de su ser y, en este sentido, el niño le teme (Morin 1985, p. 310).

Girard afirma la existencia en el ser humano, a nivel del deseo, de una íntima tendencia mimética fortalecida por las voces exteriores, que le animan y le incitan a imitar. Por la manera en cómo están hechos, los deseos y los hombres se estarían continuamente enviando señales contradictorias recíprocamente, tendiéndose trampas los unos a los otros, sin ser conscientes de estar haciéndolo ni de estar cayendo en ellas. Se trata del imperativo "imítame" que está omnipresente, al mismo tiempo que casi inmediatamente lo está el imperativo contrario: "no me imites", que resulta inexplicable y causa desesperación, provocando una esclavitud involuntaria. 
Es, como decimos, el double bind o red de dobles imperativos contradictorios, en que los hombres nos encerraríamos mutuamente y que para Girard debemos asumir como un hecho banal, como el fundamento de todas nuestras relaciones interpersonales. Y no sólo hablamos de los mensajes explícitos de los modelos, ya que "nuestra capacidad de absorción mimética no está limitada a los comportamientos los cuales nuestros modelos desean que nosotros les imitemos" (Girard 2004b, pp. 2526). En la sociedad moderna la situación sería particular en la medida en que no hay ni tabúes que prohíban a unos lo reservado para otros, ni ritos de iniciación que sirvan a los individuos para las pruebas que enfrentarán en su vida. Al contrario, "en vez de advertir al niño que las conductas imitativas serán unas veces aplaudidas y fomentadas, y otras por el contrario desaconsejadas, y que no es posible prever los resultados ni en función solamente de los modelos, ni en función solamente de los objetos, la educación moderna cree resolver todos los problemas promoviendo la espontaneidad natural del deseo, noción propiamente mitológica" (Girard 1982, pp. 328-329).

Aunque los conflictos rivalitarios y la violencia, aparejados al deseo mimético, estén mitigados o no existan en las relaciones con los adultos, siempre estarán de una u otra forma en las relaciones con los iguales (Anspach 2008, p. 184). A pesar de que Girard insiste enormemente en el mimetismo, que cree presente detrás de una multitud de fenómenos, esto no significa que excluya otro tipo de explicaciones. Así, por ejemplo, cree en el amor de los padres por los hijos y no ve posible interpretarlo de manera mimética. O piensa que el placer sexual es posible manteniendo el respeto al otro sin sombra de rivalidades, aunque sea difícil (Girard, 2006b, pp. 23-24). En la imitación habría siempre un cierto grado de "inconsciencia". Pero Girard, al contrario de la mayoría de las teorías, como la de Piaget, y en línea con lo ya dicho, no limita esta inconsciencia o los comportamientos imitativos a los primeros estadios del desarrollo psicológico humano, y también los reconoce en la edad adulta, en la que resultaría vergonzoso mostrarse deudor de aquellos a quienes se imita (Girard 2004a 53-54) ${ }^{3}$.

En el plano filogenético, según la teoría mimética, la especial aptitud humana para imitar y el deseo no fijado a los objetos habrían elevado a los seres humanos por encima de los demás animales. La falta de protección natural para controlar la violencia, también les habría hecho más vulnerables ante su desencadenamiento en el seno del grupo por cualquier causa. El mecanismo del chivo expiatorio, como

\footnotetext{
3 Toda concepción que apunte a la existencia de un deseo individual, o enraizado por completo en la historia familiar, no influenciado por los deseos de los prójimos, es rechazada por la teoría mimética. Freud nunca habría llegado a desenvolver "el misterio fundamental de dos deseos (o más) que se enfrentan en una violenta disputa porque concuerdan demasiado, porque se imitan recíprocamente". Esto, a pesar de que en sus últimos análisis habría tenido en cuenta la ausencia aguda de independencia verdadera que caracterizaría frecuentemente al pretendido narciso (Girard 1990, pp. 129-131).
} 
producto biológico y cultural, y los sucesivos sacrificios y ritos emanados de éste, habrían paliado este déficit, intentando alejar el riesgo de una violencia caótica, con una dosis de violencia controlada. Así, los vínculos sociales y la cohesión de los grupos se habrían fortalecido, contribuyendo a sostener la estabilidad social, a la vez que habrían forjado identidades comunes, a costa de las víctimas.

Pues bien, como apuntábamos al referirnos a la continuidad entre antropogénesis y ontogénesis, aún hoy, en una época post-sacrificial, podría verse en la ontogenia, en lo que a la construcción de la identidad individual y también grupal se refiere, el reflejo de la pertenencia a la especie humana, definida por Girard como la de los animales asesinos que sacralizan a sus víctimas. $Y$ es que la mayoría de las pertenencias, aún las más humildes, aunque sean positivas y necesarias, llevarían aparejadas alguna forma de exclusión, rechazo y, por lo tanto, de violencia. Se alimentarían de la exclusión de ciertos individuos y, si no se emplea físicamente la violencia, las víctimas de esta exclusión sí la percibirían como violenta: "la exclusión es una violencia tanto más amargamente sufrida por los excluidos mientras la pertenencia es o parece más deseable. $Y$, en regla general, parece tanto más deseable que ella es más difícil de adquirir" (Girard 2004b, pp. 22-23).

En nuestro pasado como especie, históricamente, en las diversas poblaciones, las pertenencias habrían estado íntimamente ligadas a la violencia. Por ejemplo, la pertenencia a la nobleza, ligada a la fuerza de las armas y al combate. Y, aunque la violencia hubiese disminuido, en la actualidad la violencia ligada a las exclusiones seguiría muy presente. Se trataría de una violencia muy desconocida, interior a las pertenencias. Cuando se aproxima a los individuos unos con otros, incitándoles a perseguir los mismos objetivos y asociaciones profesionales, educativas, deportivas... se suscita el acuerdo entre aquellos que se asemejan, ya que les inspiran los mismos deseos. Por eso también se suscitan los conflictos (Girard 2004b, pp. 2324). De nuevo, el pensador francés llama la atención sobre el hecho de que, más que las fuertes diferencias o la oposición de ideas y deseos, sería la identidad de éstos, la concurrencia por obtener las mismas cosas y la indiferenciación lo que genera mayores problemas. De este modo, la violencia no se alimentaría de la fuerza, sino de la debilidad de las pertenencias e identidades: "es porque éstas están en plena debacle que las pertenencias se dan a ellas mismas la comedia de una fuerza que ya no existe". A juicio de Girard, ni las ideologías de izquierda, ni las de derecha, aciertan a pensar las pertenencias y ambas se equivocan estrepitosamente. Cometerían el mismo error, al concebirlas de manera unívoca y unilateral (Girard 2004b, p. 33).

\subsection{La influencia de las neuronas espejo}

Curiosamente la teoría mimética de Girard, que comenzó inspirándose en fuentes literarias, y cuyo valor epistemológico podía ser cuestionado, se vería ahora apo- 
yada gracias al descubrimiento de las neuronas espejo, por un soporte biológico y neurológico, en su consideración de la imitación como comportamiento fundamental humano (y no solamente humano). El hallazgo al que nos referimos se produjo en el Instituto de neurociencias de la Universidad de Parma. Las investigaciones del equipo de Giacomo Rizzolati y Vittorio Gallese, de comienzos de los años 90, concluyeron que estas neuronas no sólo se activan cuando realizamos una acción, sino cuando observamos a alguien realizarla. Estas neuronas reflejarían el mundo exterior. La observación de la acción causa en el observador la activación automática del mismo mecanismo neuronal desencadenado por la ejecución de la acción. La imitación sería por tanto neurológica, automática, obligatoria (Oughourlian 2007, p. 166). Estas neuronas son un tipo particular de neuronas vasomotoras, descubiertas al principio en un área del córtex promotor de los monos, y que se disparan tanto en monos como en humanos al realizar una acción particular u observarla en otros. Por ello se ha utilizado la metáfora del espejo en su denominación, aunque también se conocen como neuronas de la empatía y neuronas Dalai Lama4 ${ }^{4}$ Las neuronas del individuo imitan a modo de reflejo la acción del otro, incluso emociones, facilitando el contagio de los sentimientos del otro. El observador está realizando él mismo la acción que está observando. Observar un comportamiento sería pues "realizarlo potencialmente"; cada comportamiento que observamos iniciaría en nuestro cerebro el bosquejo de este comportamiento mismo. Las neuronas espejo no sólo funcionarían en situaciones de imitación de acciones con un fin concreto, sino también previendo acciones de terceros a nivel inmediato (Bognon-Küss 2011, p. 37).

Además de hallarse en los seres humanos, tras ser antes observadas en primates, este tipo de neuronas también se ha encontrado en algunas aves. Los neurocientíficos consideran que estas neuronas tienen un papel principal en las capacidades cognitivas relacionadas con la vida social, la empatía y la imitación y para algunos se trata de uno de los descubrimientos más importantes de la última década. También hay investigadores que consideran la relevancia de las neuronas espejo para las habilidades mentales y del lenguaje. Y las disfunciones del sistema espejo podrían relacionarse con problemas como el autismo, al que aludíamos antes. De esta manera, y aunque los científicos empleen el término de "simulación incorporada" (embodied simulation), más que el de imitación o el de mímesis (Oughourlian 2007, pp. 165-167), la afirmación de la imitación, como aspecto fundamental en la ontogenia humana según la teoría girardiana, tendría un soporte científico, coincidente con algunas de las conclusiones que la teoría extraía de los genios literarios (p. ej.: la imitación y la reciprocidad como comportamientos principales, inherentes a los seres humanos). Estudios no ya neurológicos sino psicológicos, demostrarían claramente que "la imitación humana es también y sobre todo una imitación de las intenciones de otro", v. gr. "los trabajos de Harold Bekkering, que mostrarían

\footnotetext{
4 Estos nombres habrían sido propuestos por Vilayanur S. Ramachandran (Pérez Álvarez 2011, p. 21).
} 
que los niños no imitan simplemente los actos exteriores de otro, sino también sus intenciones. Incluso si las neuronas espejo no bastan para explicar todo el proceso, parece que lo acompañan" (Bognon-Küss 2011, p. 37).

Sin embargo, no habría que dejarse llevar por la euforia y el reduccionismo extremo de quienes pretenden explicar todo a partir de las neuronas espejo o el cerebro. Para algunos los temas planteados por este hallazgo obligarían a repensar o a reconsiderar algunos supuestos fundamentales, incluso, como señala M. Iacoboni, proponiendo la neuroética como una nueva disciplina. Las neuronas espejo serían uno de los descubrimientos neurocientíficos más populares de los últimos tiempos, ofreciéndose como "un nuevo comienzo en el entendimiento de la imitación, la empatía, la intersubjetividad, la publicidad, el libre albedrío, al autismo, la drogadicción, la política, la ética" (Pérez Álvarez 2011, pp. 20-21). Sin embargo, aun cuando pudiera admitirse que el descubrimiento sea decisivo para estudiar la imitación humana, permitiéndonos comprender la "rapidez" de nuestra imitación preconceptual, el sistema de las neuronas espejo sería condición necesaria, pero no suficiente, para poder imitar: "no hay que reducir la importancia de las neuronas (del cuerpo) ni el trabajo de la mente" (Bognon-Küss 2011, p. 36). La rebaja de las pretensiones explicativas de estas neuronas, es aún mayor en quienes creen que estas no son clave para comprender la imitación. Es esta, como comprobamos, una cuestión que se debate.

Así, por ejemplo, distinguiendo el nivel cerebral del psicológico, a S. De Keukelaere lo que le parece justificado de la ambición de Ramachandran (la unificación del campo de la psicología gracias a las neuronas espejo, al igual que el ADN habría unificado la biología ${ }^{5}$ ), no es la cuestión de las neuronas, sino el rol "unificador" de la imitación en psicología: "Al afirmar esto hace ya varias décadas, René Girard no fue tomado suficientemente en serio. En 2009, uno de los neurólogos que descubrió las neuronas espejo, Vittorio Gallese, afirmó que "desde un punto de vista neurocientífico", la teoría mimética de René Girard consituye un "punto de partida ideal" para un enfoque multidisciplinar de la intersubjetividad humana. Los descubrimientos de Girard se insertan de maravilla en el debate actual y desvelan al gran ausente: la reciprocidad violenta"6.

En última instancia, nos parece acertada la posición de M. Pérez cuando defiende que no hay que menoscabar la importancia de las neuronas espejo, al tiempo que rebaja el entusiasmo y las excesivas ambiciones de los neurocientíficos, como Ramachandran o Iaboconi, advirtiendo en ellos un nivel de especulación acerca del cerebro en el que van mucho más lejos de sus descripciones científicas, en un ejercicio de extralimitación. Más aún, el autor español observa atinadamente una diferencia importante entre el discurso divulgativo o para el público que aquellos man-

\footnotetext{
5 A P. Jacob esta pretensión le parece excesiva (Bognon-Küss 2011, p. 37).

6 Son palabras de S. De Keukelaere entrevistado por Bognon-Küss (2011), p. 36.
} 
tienen y sus publicaciones científicas, que corren menos el riesgo de caer en "exuberancias especulativas"7.

Girard, a través de su hipótesis de la mímesis universal, pasa en sus explicaciones del animal al hombre, del niño al adulto, de la filogénesis a la ontogenia, exponiendo una teoría del aprendizaje y una teoría general de la cultura. A continuación, una vez nos hemos hecho cargo de la ontogenia humana, tal y como se concibe en la teoría mimética, nos detendremos en bosquejar cuál sería la filosofía del sujeto que cabría colegir de la misma, de la que destacamos su oposición frontal a los postulados románticos y modernos, y que inscribiremos en el contexto filosófico contemporáneo.

\section{La filosofía interdividual del sujeto}

La preeminencia en Girard de un enfoque intersubjetivo o interdividual, que concibe a los individuos siempre en interrelación y nunca de manera aislada o solipsista, le sitúa en la órbita de los intereses antropológicos e intersubjetivos que han cobrado vigor en la filosofía actual, algo que, entre otros, no ha destacado suficientemente G. Vanheeswijck a la hora de insertarlo en las coordenadas del contexto filosófico contemporáneo. Lo hacemos aquí de manera resumida. Si sujeto deriva etimológicamente del latín subjectum, participio de pasado de subjicere (poner debajo, hacer caer debajo) (Russ 1999, p. 379), la teoría mimética subvertiría los términos, poniendo de manifiesto que, al contrario, el sujeto sería algo superficial, "puesto por arriba", siendo la dimensión intersubjetiva o interdividual la subyacente.

\subsection{Contextualización}

En oposición a las concepciones individualistas, solipsistas y autárquicas del sujeto, características del racionalismo y la Ilustración, aunque no solamente, y compartidas en otros términos por el Romanticismo (originalidad, espontaneidad, genialidad), encontramos a lo largo del s. XIX, y sobre todo en el s. XX, una impugnación progresiva de éstas. Algunos planteamientos decimonónicos son antecedentes del giro intersubjetivo y antropológico operado en la filosofía en la pasada centuria. De este modo, frente a las visiones cartesiana o kantiana $-\mathrm{y}$ también frente al individualismo burgués-, Hegel y Feuerbach asumen críticamente la Ilustración, poniendo de manifiesto el carácter social del ser humano y la relacionalidad entre

\footnotetext{
7 Podríamos ver un buen ejemplo de praxis científica en un texto que cita el autor de G. Rizzolatti y L. Craighero. M. Pérez reclama no soslayar la distinción entre neurociencia y psicología en detrimento de la segunda (Pérez Álvarez 2011, pp. 21-22, 215).
} 
el yo y el tú como algo constitutivo del sujeto o, más aún, como Marx, definiendo la esencia del hombre como el conjunto de las relaciones sociales (Pérez Tapias 2000, p. 205). También Durkheim o Freud habrían subrayado la ligazón y la interacción entre individuo y sociedad como hecho innegable. El psicoanálisis saca a flote la presencia de lo irracional en nosotros y pone en solfa al hegemónico y soberano cogito racional, mostrando sus limitaciones y sus patologías y su conexión con afectos y pulsiones (Estrada 2007, p. 35). Nietzsche, la corriente historicista y la hermenéutica continúan horadando la hasta entonces dominante concepción del sujeto. Lo hacen al plantear, respectivamente, el carácter social y sesgado del lenguaje del que no puede abstraerse el yo; la inserción del ser humano en un contexto histórico y evolutivo por el que está atravesado y su imposible deslocalización de unas coordenadas socioculturales y de una tradición (Estrada 2007, p. 35).

A lo largo del siglo XX el rechazo a la "clausura" de un yo ensimismado se patentiza en muy diversos ámbitos, formas y grados. En las filosofías de inspiración fenomenológica con Husserl, Heidegger o Merleau-Ponty, al poner el foco en el mundo de la vida y en las relaciones que en él se tejen, donde el hombre se vuelve "a las cosas mismas", "a los fenómenos", es "ser en el mundo", o la intersubjetividad se concibe como intercorporeidad. A través del giro lingüístico, en la filosofía del lenguaje, la hermenéutica (Gadamer) o las teorías de la comunicación (Habermas), negándose un acceso directo a la racionalidad que no pase por el lenguaje (individual pero aprendido); concibiendo la realidad como fenómeno intersubjetivo de sentido, enfatizando los elementos de la tradición y el contexto cultural, o considerando los prejuicios culturales y la limitación del yo y de la conciencia reflexiva, dada la existencia de una identidad prerreflexiva (Estrada 2007, pp. 36-37). Por su parte, para Ricoeur la ipseidad no puede entenderse sin la alteridad y para autores como F. Jacques o E. Benveniste no hay proceso de personificación, de asunción de identidad personal sin la inclusión de la posición del tercero, del “él”, que va más allá de la relación entre el "yo" y el "tú" (Martinez 1996, p. 373).

Con todo, como sugiere Estrada, serían las ciencias del hombre, antes que la filosofía, las que más habrían incidido en la intersubjetividad y la interrelacionalidad como hecho decisivo en la formación de la identidad personal. Como las teorías psicológicas de Piaget o Erikson (complementadas con postulados personalistas como los de Buber o Mounier), ofreciendo una teoría de la génesis de la identidad marcada por etapas de crisis y maduración (Estrada 2007, p. 37). O como la sociología de Durkheim, la psicología social de Mead, la corriente antropológica norteamericana "Cultura y personalidad" (M. Mead, C. Kluckhon, R. Benedict...) o el psicoanálisis "culturalista", que habrían sido fundamentales para comprender los procesos culturales considerando la interrelación individuo-sociedad (Pérez Tapias 2000 , p. 212). Habría que tener en cuenta también el cuestionamiento del sujeto acaecido con su deconstrucción bajo el influjo heideggeriano-nietzscheano y fou- 
caultiano en planteamientos como los de Rorty o Vattimo. No obstante lo cual no habría que confiarse ya que, a juicio de Girard, puede seguir latente una concepción romántica o moderna del deseo, que seguiría concibiendo a éste como algo "propio" o "auténtico", o ligado a un "yo", a un "inconsciente", un "da-sein" o una "voluntad de poder". Piaget, quien confirmaría a su manera los trabajos de Durkheim, Dumézil y Lévi-Strauss, afirmando que el sujeto no existe, que la relación social es lo elemental, se habría quedado, sin embargo, en una posición "binaria y dialéctica $[\ldots]$ insuficiente para explicar el mimetismo esencialmente visual, del recién nacido, mimetismo anterior a la constitución de la noción de objeto" (Morin 1985, pp. 301-302).

En este panorama, a través de la mímesis y su amplio espectro de repercusiones, Girard profundiza en el cuestionamiento del yo como inexpugnable fortaleza en la atalaya: demoliendo el muro metafísico entre animalidad y humanidad; asumiendo el carácter histórico y evolutivo del ser humano y de sus producciones culturales; derribando del trono de la engreída creación de la nada a la genialidad creativa y la innovación; borrando del frontispicio monacal del yo, de la intimidad, el amor o los deseos, el erróneo cartel de "clausura". En cambio, Girard subraya la mímesis de aprendizaje, la recepción de un legado en línea con una tradición; define deseos y emociones por su carácter mendicante, irremisiblemente ligado a los otros, y cuestiona la misma existencia del yo. Y, por tanto, también, incluso los "topónimos" que este lleva aparejado (individualidad, subjetividad, carácter, personalidad...). Dicho en términos psicoanalíticos, Girard profundiza aún más en la herida narcisista (Girard 2004a, p. 170). La torre de marfil del yo no sólo habría quedado desmochada. El yo se habría revelado como un ridículo gigante con pies de barro, que no puede entenderse sin el lodo del que está hecho y del que procede.

Curiosamente Gomá Lanzón, tras haber determinado que la teoría mimética de Girard no sería una auténtica teoría de la imitación (frente a la suya que sí lo sería), afirma dos cosas que tendría en común con él y que sin embargo obvia. Ambos comparten un mismo propósito y la misma razón que les hace compartirlo, el cuestionamiento de la noción moderna del sujeto y la facticidad de la imitación: "el sujeto kantiano autónomo, legislador de sí mismo, situado por encima del espacio y del tiempo, es incompatible con la consustancial heteronomía de la imitación, a la cual es inherente la admisión de la influencia de otro sobre el comportamiento del yo moral. Toda teoría general de la imitación deberá respetar un fenómeno fundamental que [he] denominado facticidad. Los hombres vivimos en un horizonte de modelos; sin poder evitarlo, desde antes de ser sujetos, nuestro yo está expuesto a la influencia de las conductas de los otros y ésta no cesa cuando el hombre adquiere una subjetividad autónoma. Por otra parte, no podemos evitar tampoco ser modelo constante para los demás y que nuestro comportamiento se les ofrezca a éstos como ejemplo o antiejemplo. Somos ejemplos rodeados de ejemplos, envueltos en una red 
de influencias recíprocas" (Gomá 2005, pp. 30-31). Esta cita podría ser del propio Girard salvo por dos elementos que resultarían un poco disonantes, la referencia al "yo moral" y la idea de la adquisición de "una subjetividad autónoma". Girard, en apariencia (enfatizamos, en apariencia), sólo está interesado en comprender la naturaleza humana y no en la ética. Por otro lado, hablar de "subjetividad autónoma", a la luz de lo ya visto y de su filosofía interdividual (término que aclararemos), sería a priori un despropósito. Pero también lo sería obviar que, aunque de modo no excesivamente explícito, y aunque de manera parca en palabras y citas, Girard tiene una postura más compleja de la que en principio cabría atribuirle. Así, ni la teoría mimética está ni mucho menos desprovista de una vertiente moral o de preocupaciones de índole ética, ni Girard niega absolutamente la existencia de una subjetividad. Sirvan estas palabras a modo de apunte, ya que no desarrollaremos esta problemática en este lugar.

Como hemos dicho es a través de las grandes novelas como Girard comienza construyendo el edificio teórico de la teoría mimética. Opone la verdad novelesca (la descripción del deseo como mimético en obras de grandes novelistas como Cervantes, Shakespeare, Dostoyevski...) a algunos de los enfoques de las ciencias modernas, que presuponen un sujeto descarnado o la linealidad de las relaciones de éste con sus objetos de deseo. Una de las caras de esta "verdad novelesca" es la naturaleza intersubjetiva o interdividual de los deseos y de la individualidad, algo determinante para pensar una filosofía del sujeto en Girard8.

\subsection{Definición y características}

¿Qué es el sujeto y cuáles son sus características? Girard nunca ha respondido a esta cuestión de una manera sistemática o concreta. Para clarificarla, es preciso buscar y recopilar distintos fragmentos de sus obras en los cuales habla de ella a propósito de otras cuestiones, y aplicar las consecuencias que se extraen de su teoría, y alcanzar así una dilucidación que sirva a este propósito. Y esto es lo que hemos hecho. Salvo alguna excepción podemos decir que hay coherencia sobre la cuestión del sujeto desde la primera obra hasta la actualidad.

Uno de los textos donde Girard habla de la cuestión del sujeto y del "yo" es en El misterio de nuestro mundo, obra escrita conjuntamente con Jean Michel Oughourlian y Guy Lefort. Allí, Girard dice que el sujeto es un fantasma de la verdadera estructura de reciprocidad de las relaciones humanas, que no aspira más que a la diferencia y rechaza admitir la reciprocidad. Por ello "si el loco ve doble, es

8 "Estimo que la ventaja principal de la teoría sobre el deseo mimético es que ella toma en cuenta un todo relacional. No parte del yo aislado, no parte del todo abstracto, sino que parte de aquello que yo llamaría lo "pequeño", esto es, las relaciones humanas concretas" (Girard 1991, p. 73). 
porque está demasiado cerca de la verdad", mientras que los otros, los "normales", guardan la mentira y el mito de la diferencia (Girard 1982, p. 340). Esta obra es muy interesante, dado que es aquí donde encontramos un nuevo concepto: la psicología "interdividual" (Girard 1982, p. 319). Esto quiere decir que no hay "el individuo" o el sujeto monádico, ya que el deseo, el movimiento psicológico, extraería su energía de la relación con el otro. Esta relación es la relación fundamental y, según Oughourlian, hay que verlo como una relación entre dos individuos o sujetos pero "como una relación de ida-y-vuelta, excavando/abriendo/ahuecando por su movimiento mismo en cada uno de sus polos una entidad que podría designarse como yo" (Oughourlian 2007, p. 55)9. Dicho con Girard, en referencia a su justificación de la literatura como punto de partida: "Es a partir de tres personajes que podemos hablar correctamente de relaciones humanas y nunca a partir de un sujeto solo. Es la rivalidad mimética la que es primera para mí, no el individuo. [...] La intersubjetividad es la buena dirección pero esta es reciente [en filosofía]" (Philosophie Magazine 2008, p. 58).

La verdad mimética de la constitución humana, forjada sobre los deseos ajenos y dependiente de modelos, puede ser algo desconocido para nosotros porque no sería ni objetiva ni tampoco subjetiva. Se trataría de una verdad intersubjetiva o, más bien, interdividual (Girard 1990, p. 65) y lo que llamamos nuestro "yo", nuestra "personalidad", o nuestro "temperamento" estarían fundados sobre el desconocimiento (méconnaissance) de nuestras relaciones interdividuales. Y para acceder al conocimiento de la realidad habría que cuestionar y hacer estremecer todas estas nociones individuales (Girard 1982, p. 438). De hecho, la teoría mimética pretende suprimir el punto de vista subjetivo en favor del punto de vista intersubjetivo o interdividual (Anspach 2008, p. 183). Girard afirma que no hay más que un mismo deseo para todos los hombres y que no habría razón para no afirmar a éste como el verdadero "sujeto" de la estructura. Un sujeto que se reduciría a la mímesis. El autor evita hablar en términos de "sujeto deseante" para no dar la impresión de caer en una psicología del sujeto (Girard 1982, p. 341). No obstante, si hablamos de sujeto habría que comprenderlo siempre, según la teoría mimética y en palabras de Oughourlian, "no como una entidad independiente, sino como un conjunto abierto en constante interacción con los "sujetos" que le rodean (Oughourlian 2007, Note 3 , p. 56). El "yo", añade, es "una estructura cambiante, inestable, maleable", algo que vemos ante la angustia, ante el amor, ante la muerte de un ser querido, cuando sentimos que el "yo" experimenta realmente una serie de transformaciones, ya que está constituido por las relaciones que continuamente se tejen y se destejen. La memoria, ligando los estados sucesivos de conciencia, y el olvido, disimulando el origen de los deseos, darían la impresión de una identidad permanente, pero iluso-

\footnotetext{
${ }^{9}$ Un déficit de la interdividualidad girardiana es la falta de consideración del cuerpo humano, frente a autores como Nietzsche o Merleau-Ponty.
} 
ria y siempre reconstruida a posteriori. El yo cambia sin cesar en el seno de cada relación y cada uno de nosotros estamos atravesados por la alteridad (Oughourlian 2007, pp. 56-57). Dicho más radicalmente: "El sujeto está descuartizado entre el yo y el otro" (Girard 2006b, p. 55).

Girard se pregunta irónicamente cómo es posible que la teología moderna del yo, a través de la cual románticos y modernos confieren al sujeto los atributos divinos, no haya sido completamente desacreditada y rechazada, con el resto de la metafísica occidental (Girard 2002a, pp. 312-313). Por si acaso, y aunque no dedica ninguna obra en particular, al desmontaje de esta ideología de un yo sacralizado, su "filosofía del sujeto" o, más bien, su crítica del sujeto o su filosofía interdividual, se desprenderían de su cuestionamiento de la falaz naturaleza de unos deseos pretendidamente endógenos y/o esotéricos, asociados al yo o al inconsciente: "queremos deseos marcadamente nuestros, enraizados en una historia estrictamente personal", sin embargo, "si nuestros deseos son fluctuantes, siempre dispuestos a copiar al primero que llega, ya no son la expresión del Yo profundo o aún mejor de un inconsciente inefable" (Girard 2010b, p. 12). El dinamismo del deseo mimético transgrediría las diferencias y las fronteras que se presumían demasiado estrictas entre los individuos, mostrando que la frontera entre el yo y el otro no es tan neta y que los papeles de imitador y modelo están en continuo intercambio. De este modo, frente a un yo "divino", Girard aboga por la asunción de la ambivalencia "de todo aquello que llamamos nuestro "yo", nuestra "identidad", nuestra "superioridad"”, desterrando la angustia que nos generaría seguirlo revistiendo de ese halo de sacralidad: "todas estas cosas son el galardón supremo que estamos tratando de conquis$\operatorname{tar}[\ldots]$ como atareadas hormigas, y son el más angustioso peso que desesperadamente anhelamos descargar, con preferencia en el hombro de algún otro" (Girard 1997, p. 138).

El autor cuestiona, aunque sin explicitarlos, "los grandes conceptos vacíos del humanismo" (Girard 2006a, p. 130). En cambio, cuando habla de la importancia del cristianismo al denunciar la violencia de los sacrificios rituales, la vincula al hecho de que coincidiría con el descubrimiento de éste de la noción de persona. Aunque, al mismo tiempo, afirma que el concepto utilizado importa poco ${ }^{10} \mathrm{o}$ asevera, en otro lugar, que la concepción cristiana del individuo es "lo más importante del mundo"11. Podría parecer razonable sostener que Girard no es favorable a la deconstrucción del sujeto, en tanto que la persona/sujeto sería necesaria para reconocer a las víctimas y construir el ágape fraterno. Sin embargo, en nuestra opinión, cuestionar la noción de sujeto no impediría para Girard tales cosas. De hecho, a la

10 Girard realiza esta afirmación tras haber elogiado y señalado los déficits de los planteamientos de Sartre (Girard 2006b, p. 129).

11 "The fact that there is a new type of individual in Christianity is the most important thing in the world" (Williams 1996, p. 279). 
vez que Girard deconstruye la noción de sujeto se declara contrario al aborto y la eutanasia (Girard 2006b, p. 131), y ha estampado su firma en un manifiesto internacional contra estas prácticas ${ }^{12}$. En otra ocasión también valora positivamente la noción de persona. Incluso a pesar de que esté degradada en un individualismo radical, impediría el restablecimiento de una comunidad fundada sobre la violencia unánime y el chivo expiatorio (Girard 2009a, pp. 28-29). Girard piensa que la diferencia subjetiva es algo ilusorio, pero también considera que escapar completamente al individuo significaría una renuncia absoluta al mundo, una especie de muerte viviente, como la descrita por ciertas experiencias de las grandes religiones orientales. No obstante, estas experiencias no estarían lejos de las experiencias de cambios de estado mental que tendrían lugar en las ciencias y en las artes, la mística y las conversiones religiosas, o las conversiones experimentadas por los grandes novelistas (Girard 1982, pp. 438-440). El autor de El chivo expiatorio, se muestra contrario a la noción de inconsciente de Freud. Está en contra de la idea de un aparato psíquico identificable, como una caja negra. Un inconsciente que tendría vida propia. A pesar de todo, cree que otra noción de inconsciente como desconocimiento (méconnaissance), es indispensable para comprender al ser humano. En su opinión, es la antropología mimética presente en los evangelios, la que mejor cuenta daría de ello. En particular en el Nuevo Testamento: "Padre, perdónalos porque no saben lo que hacen" (Lc 23, 24) (Girard 2004a, p. 73).

Pero Girard matiza sus críticas declarando que estas no implican "la forma de una negación total, de una destrucción radical de la idea de subjetividad, pero sería necesario abordar la cuestión del sujeto convertido que es capaz de percibirse a sí mismo como formando parte del proceso mimético" (Girard 2004a, p. 155). Esto es, contra la ignorancia y el desconocimiento que nos caracterizarían con respecto a nosotros mismos.

Hablemos ahora más concretamente de las características del sujeto, contando con el cuestionamiento de la noción misma de sujeto que hemos hecho, conforme a la teoría mimética. Repetimos que habría que considerar al sujeto, no como un fundamento o una esencia individual, sino como algo que siempre está ligado a sus relaciones con los otros. Este "yo" y sus relaciones estarían atravesados por la mímesis deseante o deseo mimético, conflictivo, rivalitario. Los filósofos idealistas creen que el "Yo" es un objeto al lado de otros, pero el "Yo" estaría constituido, en cambio, por su relación con el Otro "y no podemos considerarlo fuera de esta relación" (Girard 1976, p. 94).

El sujeto se define así por su debilidad extrema, de la cual intentaría escapar mediante la divinidad ilusoria de Otro (Girard 1985, p. 54). Para Girard hay en los hombres un apetito de trascendencia que, en general, deviene avidez de una falsa

12 http://www.mauricebignami.it/segnalazioni/Segn801fr.html. 
infinitud, y que buscarían hallar en unos modelos que se convierten en sus ídolos, a pesar de que, en realidad, todos son semejantes. Somos iguales y la soberanía personal tanto en el caso del Yo, como en el caso de los otros sería un mito, porque nunca nadie se desearía a sí mismo sino gracias a la intermediación de los otros (Girard 1976, p. 17). Frente al narcisismo, la teoría mimética defiende que los deseos que apuntalan el amor de sí, "no son simplemente los arbotantes de un edificio que existiría de manera autónoma; ellos son el edificio mismo. Si los retiramos ya no queda nada" (Girard 1990, p. 131). Comprender el deseo sería comprender que su egocentrismo es indiscernible de su altercentrismo (Girard 2009a, p. 26), que los hombres son seres vacíos de ser, imitadores rivalitarios y conflictivos, dependientes y heterónomos, por más que estén revestidos de un aparente narcisismo autocontemplativo y ataráxico.

El pensador describe la mímesis deseante como una manera de alienación más radical y profunda que la alienación económica de Marx, la sexual de Freud o la metafísica en Heidegger. La alienación mimética absorbería a las otras, ya que cada una de aquellas privilegia un dominio particular de alienación (Anspach 2008, p. 198). El ser humano no tendría deseo propio alguno, los hombres serían extraños a sus deseos y no sabrían qué desear (Girard 1986, p. 174). Y el deseo mimético "es el mismo en todos los seres humanos, independientemente de su edad, de su sexo, de su raza, de su cultura, etc." (Girard 1990, p. 146).

El deseo mimético y su reciprocidad estructurarían las relaciones humanas reglándolas y desreglándolas (Girard 1990, pp. 33 y 44) y nosotros seríamos siempre espejos los unos de los otros, siempre sumergidos en procesos permanentes de buena o mala reciprocidad, tanto en el amor como en el odio, de una manera consciente o inconsciente (Anspach 2008, p. 199), mostrando de nuevo la concepción puramente relacional del "Yo" (Girard 1990, pp. 47 y 184-185). El sujeto suele imitar sin saberlo y sin darse cuenta y, dada su vacuidad, busca un ser que está, a su vez, esencialmente fundado sobre el deseo de los deseos de los otros (Girard 2006b, p. 23 y 144); corriendo el riesgo de copiar la vacuidad de los otros y de regenerar su propio infierno (Girard 2009a, pp. 26-27). El sujeto estaría abocado inevitablemente al conflicto y a disputar los objetos que le permitirán ser como sus modelos quienes, a su vez, van a luchar también para ser como sus modelos, y que pueden ser sus mismos imitadores. Se dibuja una existencia caracterizada por el riesgo continuo de estar inmerso en una doble y mutua imitación sin tener conciencia de ello. Las rivalidades surgirán en las luchas por los mismos objetos, pero estos no son importantes una vez que los roles del sujeto y del modelo son ya intercambiables. Es entonces cuando se llegaría a una relación de doble mediación y de indiferenciación, que también habría caracterizado el estado predominante de las relaciones entre los individuos, en un estado de crisis social proclive al desarrollo de los procesos de chivo expiatorio. 
Una de las conclusiones principales que podemos colegir de esta "filosofía del sujeto", o más bien, de la intersubjetividad o interdividualidad, se ilustra en la memorable cita que sigue y que ya nos evoca la ambivalencia girardiana al respecto de la negación de la libertad y la autonomía. Si bien estas no serían negadas absolutamente, pasarían a ser consideradas de manera tan frágil como el yo. De manera que el yo y sus atributos, no podrían definirse más que teniendo siempre en cuenta el mimetismo como un lastre para estar a la altura de tan grandes fines, pero que también se revelaría como su ineludible condición de posibilidad para aspirar a ellas, nunca exentas de desarmonías. Girard define así el hecho paradójico del Yo humano como "la unidad misteriosa, en todo hombre, de la autonomía y de la heteronomía más radical. Estas dos pulsiones nos arrastran en direcciones opuestas y nunca pueden devenir complementarias pero son inseparables para siempre, puesto que ellas se alimentan la una de la otra y su emparejamiento vincula a los hombres los unos a los otros de manera inextricable, por tanto incluso aunque los divida, entre ellos y en el interior de ellos mismos. Tal es la fuente verdadera de los conflictos que oponen los hombres los unos a los otros así como a ellos mismos" (Girard 1990, pp. 183-184).

\section{Conclusión}

Llegados a este punto, hemos desarrollado la teoría ontogenética que se desprende de la filosofía antropológica mimética, incluyendo la importancia del papel de las neuronas espejo, y dibujado la filosofía interdividual del sujeto que cabe inferir de los planteamientos de Girard. Al abordar la cuestión de la ontogénesis hemos hecho hincapié en la continuidad existente con la antropogénesis en la teoría mimética. El hipermimetismo humano seguiría siendo fundamental tanto en el origen y desarrollo de la especie como en el individuo. El mimetismo y sus efectos positivos, y los conflictos generados por él, su carácter terrible e indispensable, sería cierto tanto de la cultura en conjunto como del individuo. El mimetismo y el deseo mimético serían fundamentales desde un punto de vista biológico, social y cultural, en el aprendizaje de la alimentación y el lenguaje; en la empatía, la socialización y la comunicación; en la asunción y transmisión de las tradiciones, pero también en la innovación individual y colectiva. Nuestra especial aptitud para imitar nos habilitaría para sobrepasar la animalidad tanto para bien como para mal, siendo lo más dinámico de la inteligencia humana.

La visión del ser humano dibujada por la teoría mimética en oposición, entre otros, a la filosofía moderna del sujeto, llega hasta el cuestionamiento radical de la misma noción de sujeto y no sólo de sus atributos como entidad racional, autónoma y libre sin más. La preeminencia en Girard de un enfoque intersubjetivo que 
concibe a los individuos siempre en interrelación, le inscribe en el pensamiento contemporáneo marcado por la sensibilidad antropológica e intersubjetiva, desde la asunción feuerbachiana, hegeliana y marxiana del carácter social del ser humano (frente a Descartes, Kant o el individualismo burgués), pasando por Marx, Durkheim o Freud, a la deconstrucción del sujeto de Rorty o Vattimo, y pasando por el giro lingüístico, por nombrar solamente algunos hitos.

Girard ahonda en el cuestionamiento del yo, impugnando una supuesta diferencia de carácter metafísico entre los animales humanos y el resto; asumiendo su radical condicionamiento histórico y su inserción en el contexto evolutivo, junto con los demás seres vivos; negando la excepcionalidad de los "yoes" creativos a partir de la nada o la clausura de la intimidad de deseos, pasiones y amores. Se impugna, por tanto, el sujeto autónomo, ajeno al espacio y al tiempo, incompatible con la heteronomía consustancial al sujeto imitativo, siempre expuesto a la influencia de los otros e influyendo a los otros. No obstante lo cual el pensador también valora la aportación del concepto de persona y aún siendo una ilusión, no habría que renunciar del todo al individuo y a la diferencia subjetiva, ya que considera que esto equivaldría a renunciar al mundo.

\section{Referencias bibliográficas}

Anspach, M. (dir.) (2008): Cahier René Girard, Paris, Editions de L'Herne.

Audi, R. (ed.) (2004): Diccionario Akal de Filosofia, Madrid, Akal.

BogNON-KÜs, C. (2011): "Les neurones miroirs sont-ils une clé pour comprendre l'imitation ?", en Philosophie magazine (Hors série René Girard), pp. 36-37.

Вото, L. (2005): "Entrevista: Giacomo Rizzolatti: Neurobiólogo. Las neuronas espejo te ponen en el lugar del otro", Diario El País (edición digital): http://elpais.com/diario/2005/10/19/futuro/1129672806_850215.html.

EstradA, J.A. (2007): "La identidad cultural ante los retos del s. XXI", en J.M.

Rubio y J. A. Estrada (eds.): Identidad, Historia y Sociedad, Granada, Universidad de Granada, pp. 17-54.

Gans, E. (1985): "Désir, représentation, culture" en P. Dumouchel (dir) : Violence et vérité autour de René Girard, Paris, Grasset, pp. 395-404.

GIRARD, R. (1976): Critiques dans un souterrain, Paris, Grasset.

GIRARD, R. (1982): El misterio de nuestro mundo [ed. original 1978], Salamanca, Sígueme.

GIRARD, R. (1983): La violencia y lo sagrado [ed. original 1972], Barcelona, Anagrama.

GIRARD, R. (1985): Mentira romántica y verdad novelesca [ed. original 1961], Barcelona, Anagrama. 
GIRARD, R. (1986): El chivo expiatorio [ed. original 1982], Barcelona, Anagrama. GIRARD, R. (1990): Shakespeare: les feux de l'envie, Paris, Grasset.

GIRARD, R. (1991): Sobre ídolos y sacrificios. René Girard con teólogos de la liberación [ed. original 1990], San José (Costa Rica), Ed. Dei.

GIRARD, R. (1995): “Automatismes et liberté”, en H. Grivois y J. P. Dupuy (dir.), Mécanismes mentaux, mécanismes sociaux. De la psychose à la panique, Paris. Éd. La Découverte, pp. 109-125.

GIRARD, R. (1997): Literatura, mímesis y antropología [ed. original 1978], Barcelona, Gedisa.

GiRARD, R. (2002a): La Voix méconnue du réel. Une théorie des mythes archaïques et modernes, Paris, Grasset.

GiRARD, R. (2002b): Veo a Satán caer como el relámpago [ed. original 1999], Barcelona, Anagrama.

GiRARD, R. (2004a): Los origenes de la cultura. Conversaciones con Pierpaolo Antonello y Joao Cezar de Castro [ed. original 2000], Madrid, Trotta.

Girard, R. (2004b): "Les appartenances”, en D. Mazzú (dir.) Politiques de Caïn. En dialogue avec René Girard [ed. original 1998], Paris, Desclée de Brouwer, pp. 19-33.

GIRARD, R. (2006a): Aquel por el que llega el escándalo [ed. original 2001], Madrid, Caparrós.

GIRARD, R. (2006b): Cuando empiecen a suceder estas cosas... Conversaciones con Michel Treguer [ed. original 1994], Madrid, Encuentro.

GiRARD, R. (2009a): La anorexia y el deseo mimético [ed. original 2008], Barcelona, Marbot.

GIRARD, R. (2009b): "Préface”, en Alison, J.: Le péché originel à la lumière de la Résurrection, Paris, Cerf, pp. 7-11.

GIRARD, R. (2009c) : Christianisme et modernité [ed. original 2006], Paris, Flammarion. (Con Gianni Vattimo).

GiRARD, R. (2010a): Clausewitz en los extremos [ed. original 2007], Buenos Aires, Katz.

Girard, R. (2010b): "Préface", en: J. M. Oughourlian : Psychopolitique, Paris, François-Xavier de Guibert, pp. 11-12.

GIRARD, R. (2011): Sanglantes origines [ed. original 1987], Paris, Flammarion.

GomÁ LANZÓn, J. (2005): Imitación y experiencia, Barcelona, Crítica.

LAZZERI, C. (2010): "Désir mimétique et reconnaissance", en Ch. Ramond (ed.): René Girard. La théorie mimétique: de l'apprentissage à l'apocalypse, Paris, PUF, pp. 15-57.

Martinez, M. L. (1996): Vers la réduction de la violence à l'école. Contribution à l'étude de quelques concepts pour une anthropologie relationnelle de la personne en philosophie de l'éducation, Lille, ANRT. 
Martinez, M.L. (2006): "Hacia una antropología de la frontera. R. Girard entrevistado por M.L. Martinez", en Anthropos, 213, pp. 16-34.

Maurel, O. (2009): Oui, la nature humaine est bonne! Comme la violence éducative ordinaire la pervertit depuis millénaires, Paris, Robert Laffont.

Morin, E. (2000): “Antropología de la libertad", Gazeta de Antropología, no 16, http://hdl.handle.net/10481/7495.

Morin, L. (1985): "Le désir mimétique chez l'enfant: René Girard et Jean Piaget", en P. Dumouchel (dir.): Violence et vérité autour de René Girard, Paris, Grasset, pp. 299-317.

Oughourlian, J. M. (2007): Genèse du désir, Paris, Carnets Nord.

PALADINO, F.J. (2011): "La función sacrificial de la cultura: "desnaturalizar las semejanzas". Lévi-Strauss reconsiderado desde una antropología de la violencia", Gazeta de Antropología, 27/1, http://hdl.handle.net/10481/15341.

Pérez Álvarez, M. (2011): El mito del cerebro creador. Cuerpo, conducta y cultura, Madrid, Alianza.

PÉrez TAPIAs, J.A. (2000): Filosofía y critica de la cultura, Madrid, Trotta.

RAMOND, Ch. (coord.) (2010): La théorie mimétique: de l'apprentissage à l'apocalypse. Paris, PUF.

Russ, J. (1999): Léxico de Filosofía, Madrid, Akal.

SÁEz, L. (2001): Movimientos filosóficos actuales, Madrid, Trotta.

SEIBEL, C. (1985): "Désir mimétique et échec scolaire", en P. Dumouchel (dir.): Violence et vérité autour de René Girard, Paris, Grasset, pp. 287-298.

Williams, J.G. (1996): "The Anthropology of the Cross: A Conversation with René Girard", en R. Girard: The Girard Reader, edited by J. G. Williams, New York, Crossroad Herder, pp. 262-288.

Agustín Moreno Fernández

Facultad de Filosofía

Universidad de Granada

morenofdez@ugr.es 